\title{
Asthma: correct use of inhalation drug-delivery devices
}

\author{
José R. Fernández-Soto ${ }^{1}$, Elsy M. Navarrete-Rodríguez ${ }^{1 *}$, Blanca E. Del-Río-Navarro ${ }^{1}$, \\ Omar J. Saucedo-Ramírez', Jaime M. Del-Río-Chivardi', Néstor A. Meneses-Sánchez', \\ Laura Gochicoa-Range ${ }^{2}$ and Juan J. Sienra-Monge ${ }^{3}$
}

${ }^{1}$ Servicio de Alergia e Inmunología, Hospital Infantil de México Federico Gómez; ${ }^{2}$ Departamento de Fisiología Respiratoria, Instituto Nacional de

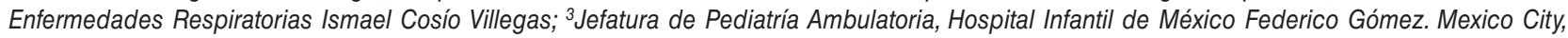
Mexico

\begin{abstract}
Inhaled therapy is considered the cornerstone of asthma treatment. However, despite being the ideal form of drug delivery, it is recognized that only $70 \%$ of patients have an adequate attachment to their treatment and only $39-67 \%$ of physicians can explain the optimal inhaler technique. Inhaled therapy has very specific characteristics. Pulmonary deposit of an inhaled medication through the respiratory tract is more complex than when administered orally and depends on several factors inherent to both the medication and the administration. For successful inhaled therapy, the drug needs to be converted into particles of an appropriate size, which can enter beyond the oropharynx and larynx, and be deposited in the lungs. There are multiple devices for the administration of drugs in the lower respiratory tract, each one with a similar efficacy as long as it is used with the correct technique. The decision of which device should be used is made based on the age of the patient, the ability to coordinate between the inhalation and activation of the device, and the presence of acute symptoms. The choice of the device must be evaluated individually.
\end{abstract}

Key words: Asthma. Nebulizers. Vaporizers. Inhalation. Treatment.

\section{Asma: uso adecuado de dispositivos para inhalación}

\section{Resumen}

La terapia inhalada se considera la piedra angular del manejo del asma. Sin embargo, a pesar de ser la forma ideal de administración de estos medicamentos, solamente el 70\% de los pacientes cumple el tratamiento adecuadamente y sólo del 39 al 67\% de los médicos conocen y pueden explicar de forma adecuada las distintas técnicas de inhalación. La terapia inhalada tiene características muy particulares. El depósito pulmonar de un medicamento inhalado a través del tracto respiratorio es más complejo que cuando se administra por vía oral, y varía dependiendo de varios factores, tanto inherentes al medicamento como a la forma de administrarlo. Para que la terapia inhalada sea exitosa, se requiere que se generen partículas del medicamento de un tamaño apropiado que penetren más allá de la orofaringe y la laringe, y que puedan depositarse en los pulmones. Existen múltiples dispositivos para la administración de medicamentos en la vía respiratoria baja. Cada uno ha probado tener una eficacia similar, siempre y cuando se utilicen con la técnica correcta. La decisión para

Correspondence:

*Elsy Maureen Navarrete-Rodríguez E-mail: draenavarrete@gmail.com

2444-3409/@ 2018. Hospital Infantil de México Federico Gómez, published by Permanyer México SA de CV, all rights reserved.
Available online: $30-10-2019$ 
su uso se realiza con base en la edad del paciente, la capacidad de coordinar entre la inhalación y la activación del dispositivo y la presencia de síntomas agudos. La elección del dispositivo a utilizar siempre deberá hacerse de forma conjunta, evaluando pros y contras de cada uno de los dispositivos y siempre de forma individualizada.

Palabras clave: Asma. Nebulizadores. Vaporizadores. Inhalaciones. Tratamiento.

\section{Introduction}

Asthma is a serious health problem worldwide. It currently affects more than 300 million people $^{1}$ and has an estimated prevalence of 1 to $18 \%{ }^{2}$. Its frequency has been increasing in recent years, and given the importance of this condition and the economic impact of its inadequate management, many efforts have been made to improve the treatment of patients who present it.

It is well known that the cornerstone of asthma management is inhaled therapy ${ }^{3}$. However, it is recognized that only $70 \%$ of patients comply adequately with treatment $^{4}$, and only 39 to $67 \%$ of physicians know and can explain the appropriate inhalation techniques ${ }^{5}$.

The first known reference to the administration of an aerosol for therapeutic purposes is the papyrus of Ebers (1554 BC), which describes the inhalation of the vapor released by plants of black henbane (Hyoscyamus niger) in patients with breathing difficulty ${ }^{6}$. It was not until 1858 that the first "pressurized" inhaler, invented by Sales Girons in France, was presented at the Paris Academy of Medicine. Six years later, in London, Newton patented an inhalation device for the administration of dry powder medication?. By the spring of 1955, the daughter of the CEO of Riker Laboratories, Inc., asked her father why she could not have her asthma medication in an aerosol can, like the hair spray ${ }^{8}$. At that time, patients with asthma administered their bronchodilator medication through a handheld nebulizer without the possibility of measuring an accurate dose ${ }^{9}$, which caused significant variation in the therapeutic effects. In the summer of that year, the first clinical trials with a pressurized metered-dose inhaler (pMDI) prototype were started, demonstrating its efficacy. The first pMDI, isoproterenol sulfate with epinephrine bitartrate, was launched in March $1956^{8}$. In the following decade, the development of spacers and chambers with a check valve began, which has shown that in order to achieve control of the asthma symptoms, not only the type of drug is essential, but also the device and the technique used for its administration?.

When discussing inhaled therapy, its particular characteristics should be considered. The lung deposition of an inhaled medication through the respiratory tract is more complicated than when administered orally and varies depending on several factors, both inherent to the subject and the medication, and how the last is administered.

Within-subjects factors, both the geometry of the bronchial tree along with the ventilatory pattern and pulmonary mechanics must be considered. Both factors are described below:

- The geometry of the bronchial tree. The airways have approximately 23 bronchial generations: the first 14 have smooth circumferential muscle and cartilage and correspond to $5 \%$ of the total bronchial tree; the last seven cover $95 \%$ of the surface of the airway and do not present cartilage. Stretching and traction are what allow this section to maintain its permeability ${ }^{4}$. Due to the above, it is assumed that different drugs are directed to different regions. For example, $\beta 2$-agonists generally target proximal airways generations containing circumferential smooth muscle, while steroids have a more uniform distribution since their receptors are present throughout the entire airway ${ }^{10}$. To this fact, it should be added that there is a change in the circumferential diameter of the airway as it progresses in each generation so that the size of the administered drug particle will directly influence the site of its deposition.

- Ventilatory pattern and pulmonary mechanics. The degree of lung disease at the time of inhalation also significantly influences lung deposition: inflammation, mucus hypersecretion, and bronchoconstriction reduce the diameter of the airways and increase the speed of airflow and turbulence, which causes drug deposition in the proximal respiratory tract ${ }^{11}$. Another fact to take into consideration is that children have smaller airways than adults, and it is likely that the airways of asthmatic patients are narrower than the airways of healthy subjects, due to inflammation, remodeling, and bronchoconstriction, which are features of this condition ${ }^{12}$.

Regarding the factors inherent to the drug, among the most important are the particle size, the speed of entry, the hygroscopic growth, and the electrostatic charge:

- Size of the particle. For the inhaled therapy to be successful, it is required the generation of drug particles that penetrate beyond the oropharynx and the larynx and that are deposited in the small airway ${ }^{3}$. 
Since aerosols generate particles of various sizes, just like dry powder inhalers (DPIs) ${ }^{1}$, an «average» measure, known as mass median aerodynamic diameter (MMAD), is used, which means that $50 \%$ of the aerosol particles are smaller and $50 \%$ are larger than the reported MMAD value ${ }^{4}$.

- The aerodynamic diameter is considered the most critical factor related to the particle that affects the aerosol deposition ${ }^{10}$. Particles $>5 \mu \mathrm{m}$ are more likely to be deposited by impaction on the oropharynx and swallowed; ${ }^{13} 4$ to $5 \mu \mathrm{m}$ particles are deposited primarily in the bronchial/conductive airways, and the smallest particles remain in the air stream and are carried to the peripheral and alveolar regions (Fig. 1). Upon entering the airway, the particles will be deposited by three mechanisms: impaction, sedimentation, and diffusion, depending on the speed of inhalation and the size of the particle:

- Impaction. It is caused by the collision of aerosol particles in the airway and generally takes place with particles $>5 \mu \mathrm{m}$ that are administered with a high firing or discharge velocity, and high inspiratory flow. The first depends on the device, and the second, on the patient. This mechanism is crucial for the deposition of drugs in the first seven generations of bronchi $\mathrm{i}^{4,13}$ and occurs mainly with $\beta 2$-adrenergic agonists. If the patient is crying, the medication administration should be avoided since it increases the drug impaction. It is recommended to perform slow and stable inhalations by calm patients and to consider that if a metered-dose inhaler is used, it must be accompanied by a spacer chamber with the appropriate technique.

- Sedimentation. It is the settlement of particles between $0.5-5 \mu \mathrm{m}$ of size due to gravity ${ }^{13}$. It occurs predominantly in medium-sized airways and beyond the eighth bronchial generation, where the air velocity is lower ${ }^{4}$. The sedimentation is favored during a deep inhalation accompanied by the highest possible postponement of the exhalation so that the particles precipitate by gravity and reach a higher pulmonary deposition.

- Diffusion. It affects small particles $(<1 \mu \mathrm{m})$ in regions of low pulmonary flow, where the random particle movement, called Brownian movement, has a more significant influence than gravity (Fig. 2$)^{14}$. Although small particles $(\approx 1 \mu \mathrm{m})$ have a greater potential to be exhaled (10\% of the dose), most of the dose is deposited at the pulmonary level $(60 \%)$, and a much lower amount at the oropharyngeal level $(30 \%)^{15}$.

- Entrance velocity. The airflow directly influences the impaction of the particles on the walls of the airways

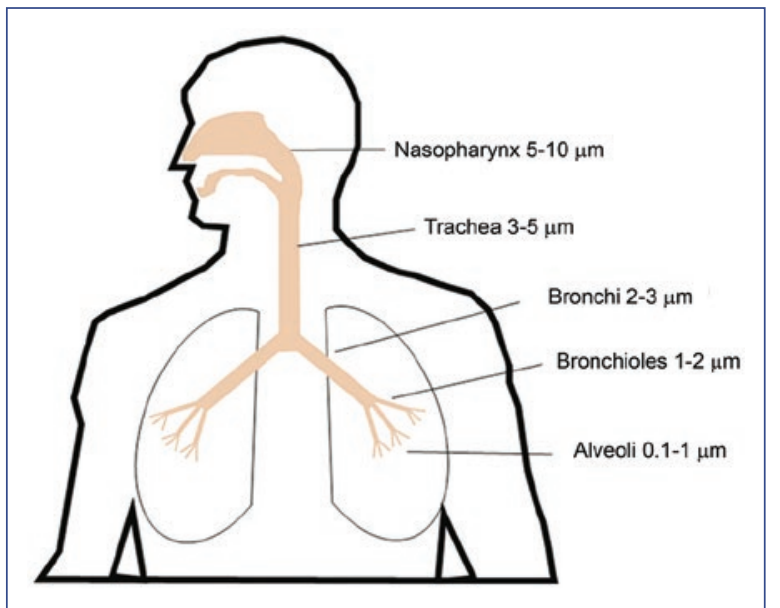

Figure 1. Size of inhalable particles concerning the diameter of the respiratory tract.

and is one of the most critical aspects of the pulmonary deposition. A slow and deep inhalation after a deep exhalation, lasting 2 to $3 \mathrm{~s}$ in children and from 4 to $5 \mathrm{~s}$ in adults, generates flows of $30 \mathrm{l} / \mathrm{min}$, which are ideal for pMDI and minimum for $\mathrm{DPI}^{16}$. An inspiratory flow greater than $60 \mathrm{l} / \mathrm{min}$ increases the impaction on the oropharynx and upper respiratory tract, so a sudden inspiration should be avoided. With the use of spacing chambers, the entrance velocity and oropharyngeal deposition are decreased.

- Hygroscopic growth. The addition and removal of water can significantly affect the size of particles from a hygroscopic aerosol (which tends to absorb humidity from the environment) and their deposition. Some particles may increase in size in high humidity conditions. This growth is based on the initial particle diameter: if it is $<1 \mathrm{~mm}$, it can increase up to five times its size, while if it is $>2 \mathrm{~mm}$, the size can increase up to three times. The airway humidity is sufficient to generate these changes.

The increase in particle size above its initial size affects the amount of drug deposited and, particularly, its distribution in the respiratory tract ${ }^{13}$.

- Electrostatic charge. The availability of the aerosol medication can be affected by electrostatic charges present during its generation or transport, which affects the pulmonary deposition ${ }^{17}$. The electrostatic charge of the aerosols can vary depending on the formulation, the material used in the devices, and the spacing chambers. Several strategies have been implemented to improve medication availability in the respiratory tract. These include the use of antistatic 


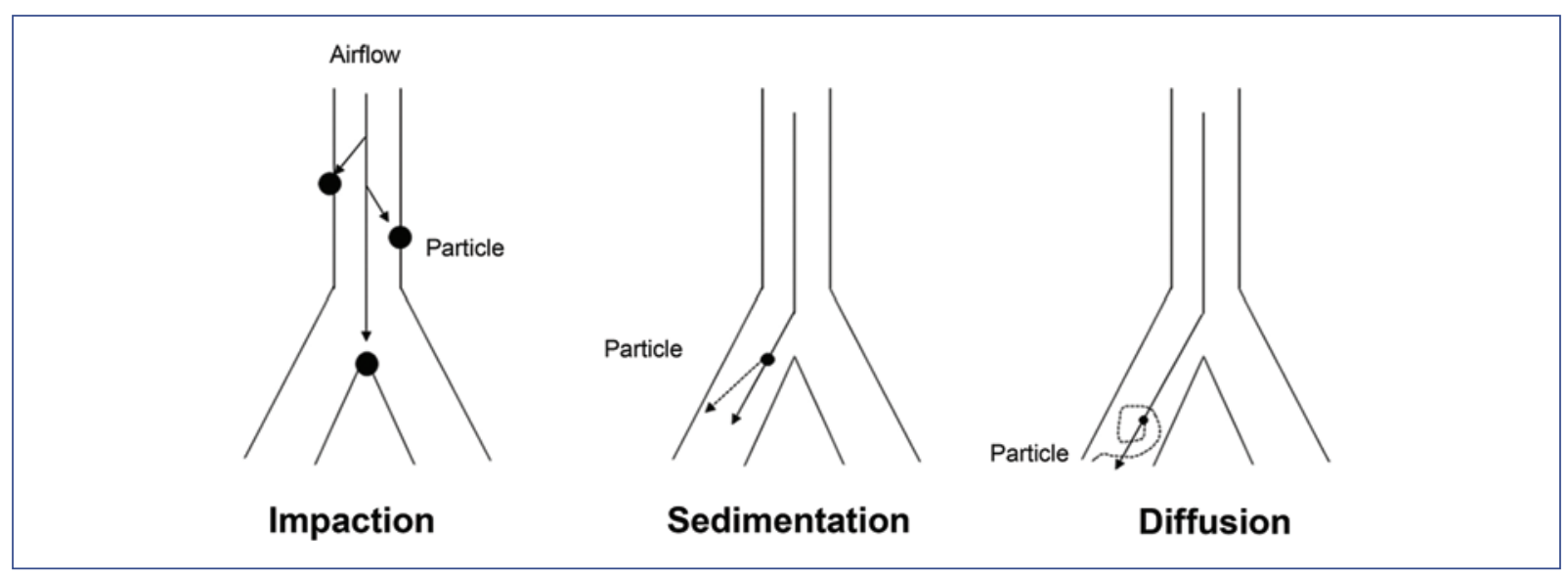

Figure 2. Mechanisms of pulmonary deposition (modified from Muchão et $a \Gamma^{4}$.).

materials in the inhalation devices or priming the walls of the spacer chamber with 20 doses of the medication in order to coat the inner surface minimizing the static charge. Currently, the most practical and least expensive solution is to use non-conductive spacers, wash them with dish detergent, and dry them outdoors to allow a better final delivery of the medication ${ }^{18}$.

\section{Method of administration: type of device}

The success of inhaled therapy depends on the appropriate choice of drug, the selection of the device by which it will be administered ${ }^{15}$, and the correct training for its use.

A large number of inhalation devices have been designed recently. In general, it is assumed that the ideal device should have the following characteristics:

- Effective: It allows the inhalation of drug particles $\leq 6$ $\mu \mathrm{m}$, regardless of the inspiratory flow of the patient.

- Reproducible: It allows the inhalation of the same amount of medication always.

- Precise: It allows knowing the number of doses of the medication remaining in the device.

- Stable: It can protect the medicine from the effects of temperature and humidity changes.

- Comfortable: It is easy to use, easily transportable, small in size, and multi-dose.

- Versatile: It allows the use of different combinations of medications for inhalation.

- Friendly with the environment: It should not contain chemical contaminants or damage the ozone layer.

- Affordable: It has a fair price, and it is rechargeable ${ }^{19}$. At present, the devices are grouped depending on the type and form of drug administration:
- pMDI

- DPI

- Soft mist inhalers

- Mechanical and ultrasonic nebulizers

All have proven similar efficacy, as long as they are used with the correct technique ${ }^{20}$. The decision of its use is made based on the age of the patient, the ability to coordinate between inhalation and device activation, and the presence of asthma symptoms (because it affects the inspiratory flow) ${ }^{21}$. Once these factors are considered, and after having instructed the patient about the specific technique for the device, the health professional must request a demonstration to make sure that it is done correctly.

\section{Pressurized metered-dose inhalers}

One of the first devices that were used, whose main innovation was the portability. Before them, apparatuses of considerable size were used to nebulize the medication. Another advantage of its use was the practicality: with an adequate technique of deep inhalation, the dose of the desired drug alone could be administered and, finally, the characteristic of being multidose.

The pMDI is a device that generates an aerosol (a two-phase system, defined as the dispersion of a suspension of solid particles or liquid droplets in a gaseous medium) ${ }^{22}$ by using a pressurized aluminum cartridge containing the micronized drug in a suspension with ethanol, as a cosolvent, and hydrofluoroalkane (HFA), as a propellant. For several decades chlorofluorocarbon (CFC) was used as a propellant for pMDI; however, this gas damages the ozone layer. Because of the signing of the Montreal Protocol in 1987, it was 


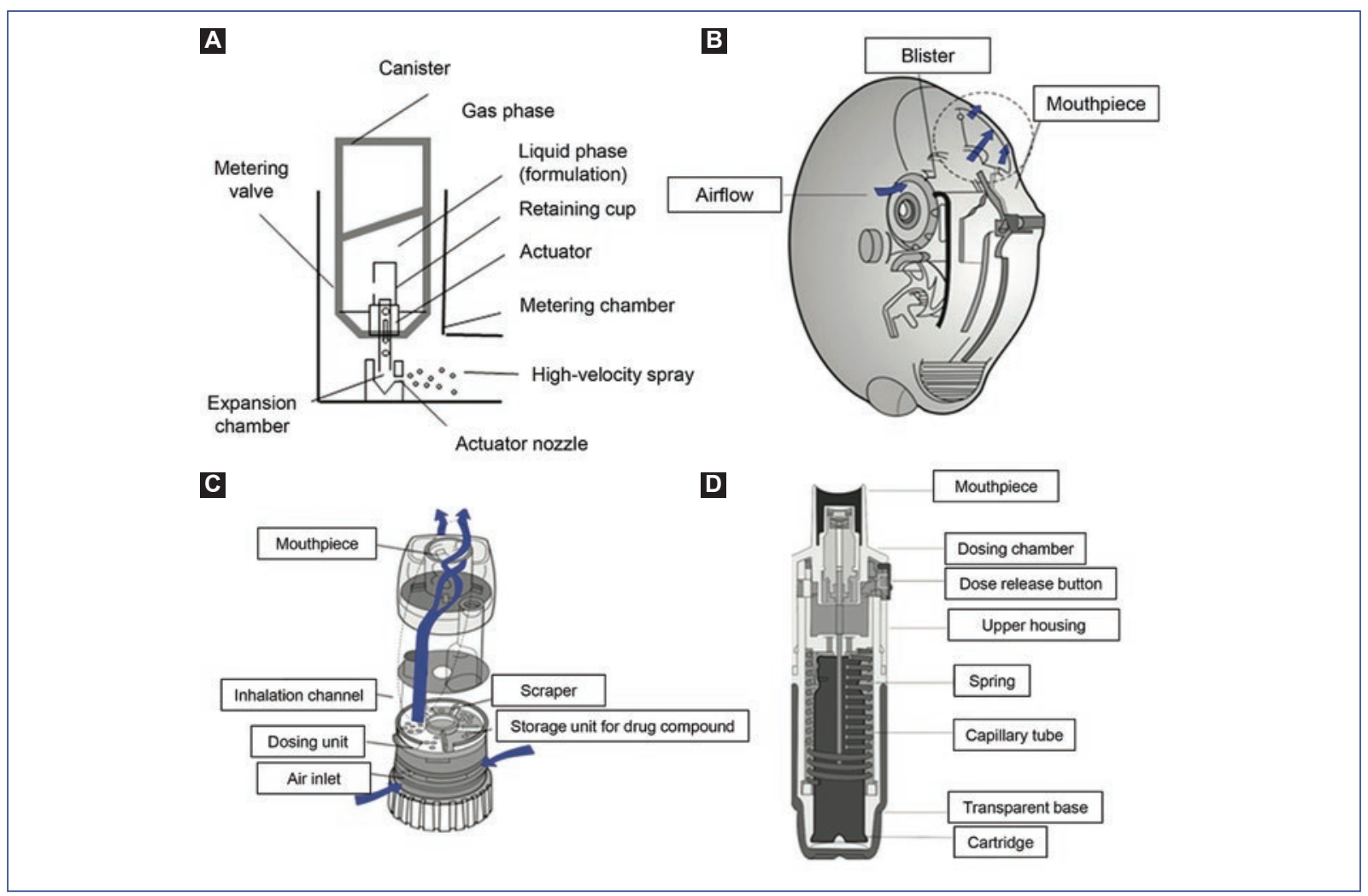

Figure 3. Key components of the devices: pressurized metered-dose inhalers (A); dry powder inhalers Diskus ${ }^{\circledR}(\mathbf{B})$ and Turbuhaler ${ }^{\circledR}$ (C); and Respimat ${ }^{\circledR}$ (D) (modified from Newman and Azouz et a ${ }^{26,27}$.).

established changing the CFC for HFA, which does not affect the ozone layer ${ }^{23}$.

The structural components of the conventional pMDI are the canister, metering valve, actuator, mouthpiece, formulation, and propellant ${ }^{24}$. The suspension of the drug is at a pressure of 3 to 4 atmospheres and generates particles of 2 to $4 \mu \mathrm{m}$. The metering valve is designed to deliver a precise amount of aerosol $(20-100 \mu l)$ each time the device is activated. When the inhaler is not used, an internal valve between the canister and the metering chamber opens, allowing the chamber to fill with a propellant-drug mixture in liquid form. At the same time, another external valve between the metering chamber and the outside air closes. While the patient presses the canister to activate the dose, the internal valve closes, and the external one opens, releasing the drug-propellant mixture, retained in the chamber, through the orifice of the actuator in the form of an aerosol. Internally, the actuator includes an atomizing nozzle (orifice of the actuator) and the expansion chamber, in which the propellant released from the metering chamber expands and partially volatilizes due to the decrease in pressure (Fig 3) ${ }^{25-27}$.
Worldwide, pMDI are the most widely used inhalation devices for the treatment of asthma and chronic obstructive pulmonary disease (Table 1$)^{3}$.

\section{Pressurized metered-dose inHalers With a SPACER DEVICE}

A spacer is an extension device located between the patient and the $\mathrm{pMDI}^{28}$. These devices help to improve the efficiency of pressurized cartridges by increasing the distance between the mouth and the device, which decreases the flow velocity of the aerosol and the impaction on the oropharynx and allows the freon evaporation and the decrease of the particle size. Besides, they facilitate lung penetration and deposition (greater than $30 \%)$.

Several factors influence its effectiveness, the space between the entrance and the exit of the inhaler, the material from which they are made, the inhalation technique, and the general care of the device.

There are different types of spacers: the open tube, the reverse flow design in which the pMDI is located close to the mouth and is fired away from the patient, 
Table 1. Available drugs in Mexico in pMDI, DPI and soft mist devices

\begin{tabular}{|c|c|c|c|}
\hline & Type of drug & Generic name & Brands \\
\hline \multirow[t]{9}{*}{ pMDI } & \multirow[t]{2}{*}{ Short-acting bronchodilators } & Salbutamol & $\begin{array}{l}\text { Ventolin }^{\circledR}, \text { Assal }^{\circledR}, \text { Aurosal }^{\circledR}, \text { Farmarest }^{\circledR}, \\
\text { Inbumed }^{\circledR}, \text { Salamol }^{\circledR}, \text { Salbutalan }^{\circledR}\end{array}$ \\
\hline & & Ipratropium bromide & Atopyo ${ }^{\circledR}$ y Atrovent ${ }^{\circledR}$ \\
\hline & \multirow[t]{4}{*}{ Inhaled steroids medications } & Beclomethasone & $\begin{array}{l}\text { Ovar }^{\circledR}, \text { Baclonet }^{\circledR}, \text { Beclazone }^{\circledR}, \text { Dobipro }^{\circledR}, \\
\text { Mizraba }\end{array}$ \\
\hline & & Ciclesonide & Alvesco ${ }^{\circledR}$ \\
\hline & & Fluticasone & Flixotide ${ }^{\circledR}$ \\
\hline & & Budesonide & Numark $^{\circledR}$, Aerosial ${ }^{\circledR}$, Jagodi ${ }^{\circledR}$ \\
\hline & \multirow{3}{*}{$\begin{array}{l}\text { Combination therapy of inhaled } \\
\text { steroids and long-acting } \\
\text { bronchodilators }\end{array}$} & Fluticasone with salmeterol & Seretide Evohaler ${ }^{\circledR}$, Lasfligen ${ }^{\circledR}$ \\
\hline & & Budesonide with formoterol & Vannair $^{\circledR}$ \\
\hline & & Mometasone with formoterol & Zenhale $^{\circledR}$ \\
\hline \multirow[t]{10}{*}{ DPI } & \multirow[t]{3}{*}{ Inhaled steroids medications } & \multirow[t]{2}{*}{ Budesonide } & Single-dose: Miflonide Aerolizer ${ }^{\circledR}$ \\
\hline & & & Multi-dose: Pulmicort Turbuhaler ${ }^{\circledR}$ \\
\hline & & Mometasone & Multi-dose: Elovent Twisthaler ${ }^{\circledR}$ \\
\hline & \multirow{6}{*}{$\begin{array}{l}\text { Combination therapy of inhaled } \\
\text { steroids and long-acting } \\
\text { bronchodilators }\end{array}$} & \multirow[t]{2}{*}{ Fluticasone with salmeterol } & Single-dose: Nimbus y Ulfhinlas ${ }^{\circledR}$ \\
\hline & & & $\begin{array}{l}\text { Multi-dose: Seretide Diskus e Irflosol } \\
\text { Forspiro }^{\circledR}\end{array}$ \\
\hline & & Budesonide with formoterol & Multi-dose: Symbicort Turbuhaler ${ }^{\circledR}$ \\
\hline & & Aclidinium bromide with formoterol & Single-dose: Duaklir Genuair ${ }^{\circledR}$ \\
\hline & & Beclomethasone with formoterol & Multidose: Innovair Nexthaler ${ }^{\circledR}$ \\
\hline & & $\begin{array}{l}\text { Vilanterol trifenatate with } \\
\text { fluticasone }\end{array}$ & Multidose: Relvar Ellipta ${ }^{\circledR}$ \\
\hline & Long-acting bronchodilators & Formoterol fumarate & Multidose: 0xis Turbuhaler ${ }^{\circledR}$ \\
\hline \multirow[t]{2}{*}{$\begin{array}{l}\text { Soft mist } \\
\text { device }\end{array}$} & Short-acting bronchodilator & $\begin{array}{l}\text { Salbutamol and ipratropium } \\
\text { bromide }\end{array}$ & Combivent Respimat $^{\circledR}$ \\
\hline & Long-acting bronchodilator & Tiotropium & Spiriva Respimat ${ }^{\circledR}$ \\
\hline
\end{tabular}

DPI, dry powder inhaler; pMDI, pressurized metered-dose inhaler.

and the reservoir or holding chamber, which is the most used and allows keeping the aerosol inside the camera for a finite time (Fig. 4) $)^{3,29}$. There are spacers of great size diversity: from $50 \mathrm{ml}$ to $750 \mathrm{ml}$, which can impact the total amount of the drug that is deposited in the oropharynx or the lungs. When the spacer is small, less medication is deposited at the pulmonary level and more at the oropharyngeal level. Conversely, by increasing the spacer capacity, there is a better deposition at the pulmonary level and less at the oropharyngeal level. However, when dealing with patients with a small tidal volume (children $\leq 2$ years), a large spacing volume requires more prolonged administration times ${ }^{30}$.
Studies show that different spacer devices increase the bioavailability of inhaled medication ${ }^{31,32}$. However, the fundamental issue for the delivery of the medication is an adequate technique ${ }^{33,34}$.

Despite the differences between the spacers, all the designs have some inherent advantages:

- They reduce the velocity of pMDI particles, which occurs during the time that the aerosol passes through the length of the spacer or valved holding chamber.

- They increase the fraction of FPF fine particles due to the impaction of the larger particles of the drug and the partial evaporation of the propellant inside the chamber ${ }^{35}$. 


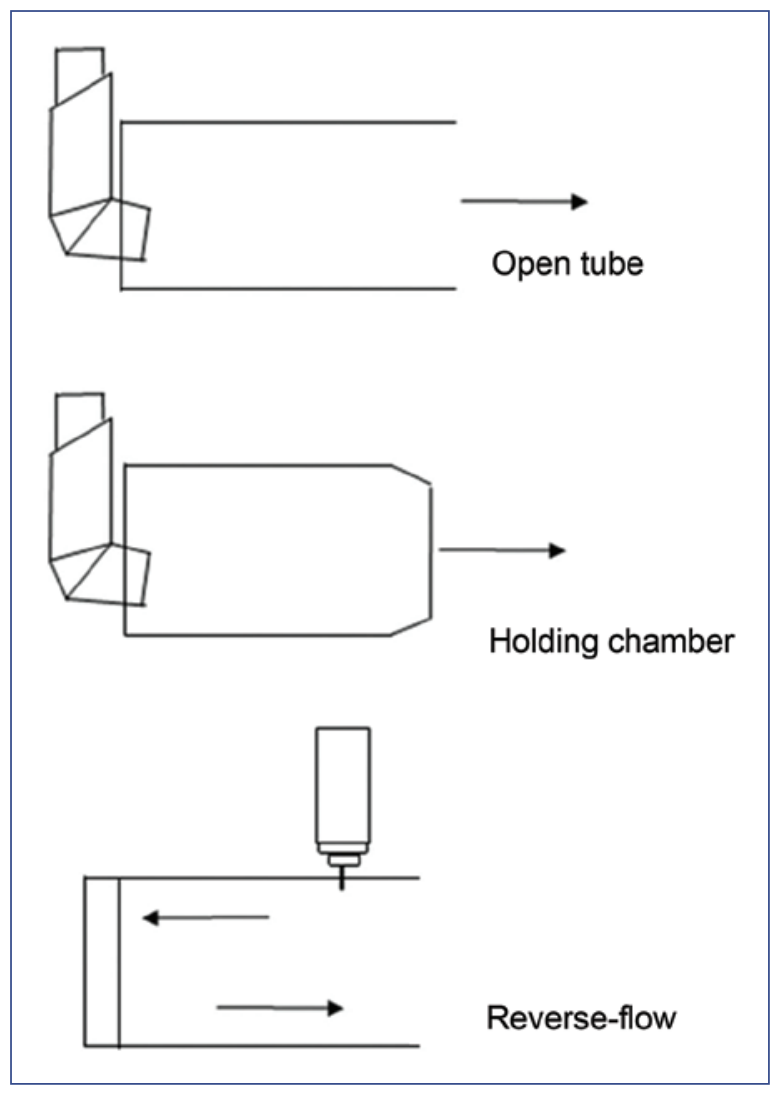

Figure 4. Types of complementary devices (spacer chamber) for pressurized metered-dose inhalers (modified from Adkinson et $a^{29}$.).

- They overcome, in part, the problem of coordinating activation with inhalation, thus increasing lung deposition. However, coordination is necessary, since delays in inhalation have been shown to reduce lung delivery significantly ${ }^{36}$.

- They can be used at any age, even in patients with mechanical ventilation and tracheostomy.

- They do not produce cough or reflex bronchospasm, which sometimes occurs with the use of pMDI without a spacer.

Because they reduce the impaction on the oropharynx, spacers and valve retention chambers are recommended primarily for the use of corticosteroids. However, even in this case, it is essential to rinse the patient's mouth after inhaling a corticosteroid with these devices, to remove the impacted particles in the oropharyn $x^{10}$.

Most of the spacers are made of non-conductive plastic materials: aerosolization and daily handling, induce an electrostatic charge on their internal and external surface. The net effect of these electrostatic charges is the attraction of aerosol particles towards the walls and the significant reduction of the available dose of aerosol for inhalation ${ }^{37}$. Some spacers "without static" have been developed, which are based on the type of plastic material used or the presence of a thin metal layer on its inner surface that reduces static. The aerosol remains suspended for more extended periods in the retention chambers with this type of materials ${ }^{38}$.

A recommendation to decrease the static is to wash both new and previously used devices with dilute liquid dishwashing detergent, do not rinse them, and let them air dry. These measures will allow a coating of this material to accumulate inside the spacer, which will decrease the static ${ }^{37,39}$, and will increase the medication delivery. The effect of the detergent coating on the electrostatic charge decreases after one week ${ }^{40}$, but the efficiency of the drug deposition at the pulmonary level is still maintained for four weeks, so it is recommended to repeat the washing at this moment ${ }^{41}$.

The main disadvantage of this type of devices is that they are generally bulky and less portable than a pMDI.

\section{BREATH-ACTUATED METERED-DOSE INHALERS}

They were developed to overcome the problem of poor activation-inhalation coordination with the standard pMDI. The currently available inhaled activated pressurized metered-dose inhalers (BA-pMDI) are the Autohaler $^{\circledR}$, which is automatically operated at inspiratory flow rates of $\approx 30 \mathrm{l} / \mathrm{min}$, and the Easi-Breathe ${ }^{\circledR}$, which is activated at $20 \mathrm{l} / \mathrm{min}^{10}$.

\section{Dry powder inhalers}

In the early seventies, the first DPI in the US appeared ${ }^{42}$, which was presented as a more environment-friendly option (as it did not contain fluorinated products), with more chemical stability than liquid formulations ${ }^{28}$ and required minimal coordination between respiration and activation of the device ${ }^{43}$. The first to appear was the Spinhaler ${ }^{\circledR}$, a single-dose device that worked by piercing a capsule that was manually deposited in a slot and was inhaled by a mouthpiece. As the years went by, improvements were added to the design, including multi-dose devices and carrier substances that allowed better delivery at the pulmonary level.

Currently, there are two basic DPI types depending on the number of doses that they can carry: single dose, in which the medication is delivered in individual capsules that are manually deposited by the patient, and multidose, which use doses measured and sealed at 
the factory, packed in such a way that the device does not have to be recharged. Of the latter, some have a bulk formulation in a reservoir and a built-in mechanism to measure individual doses after activation, and those that have pre-measured doses dispensed from the factory inside disks, cartridges, or strips packed in blister packs $^{10}$.

From the design point of view, the DPI principal parts are the same for all types of devices, which consist of a powder formulation, a dosing mechanism that contains (or measures) a single medication dose, a powder deagglomeration system, which disperses the powder in the inhaled air, and a mouthpiece (Fig 3$)^{44}$.

Currently available DPIs are classified as passive devices, because they use the energy of the vibration exerted by the patient when inhaling on the mouthpiece to facilitate the medication deagglomeration ${ }^{6}$ and, therefore, the delivery of the dose depends on the patient's inspiratory effort. For each inhaler, there is a minimum of energy, that is, the inspiratory flow required to provide an efficient formulation deagglomeration. Below the minimum energy threshold, the patient will not have the therapeutic medication effect. Most commercially available DPIs require a peak inspiratory flow rate between 30 and $60 \mathrm{l} / \mathrm{min}$ for powder delivery, with some variations in different devices. It should be considered that children, elderly, and those who experience a severe exacerbation may not be able to generate sufficient inspiratory flow for its proper functioning, for which the use of a different inhalation device will be required in these patients.

In general, current DPIs have an average deposition in the airways between 40 and $80 \%$ of the measured dose $^{45}$ (with an adequate inhalation technique), which is similar and even slightly better than those observed in $\mathrm{pMDI}^{29}$. Most of these devices rely on the use of a carrier substance (lactose or glucose) that mixes with the medication and allows the powder to pass more easily out of the device. Most of these particles, due to their size $(20-65 \mu \mathrm{m})$, are deposited in the oropharynx (so mouthwash should always be recommended), and this allows the smaller particles of the drug $(1-2 \mu \mathrm{m})$ to be delivered to the pulmonary level ${ }^{29}$.

One point to consider is that humidity can markedly affect the medication supplied by the DPI. The dose delivered at the pulmonary level decreases in a humid environment, probably as a result of the powder agglutination produced by the added humidity. Therefore, it is very important to store the DPI in a cold and dry environment. Another disadvantage is that these devices cannot be used in patients with mechanical ventilation or tracheostomy.
Currently, different DPI devices are used: Turbuhaler ${ }^{\circledR}$, Diskus $^{\circledR}$, Eklira $^{\circledR}$, Irflosol ${ }^{\circledR}$, Twisthaler ${ }^{\circledR}$, Ellipta $^{\circledR}$, Diskhal$\mathrm{er}^{\circledR}$. In general, all of them work under the same principle and only differ in some specifications, such as inspiratory flow, use of carriers, and design (Table 1$)^{46}$.

\section{Soft mist inhalers}

The idea of developing this type of device was to combine the advantages of pMDI and nebulizers. They are small portable and manual inhalers, which do not require an energy supplement (such as pMDI) to release the medication. They are propellant-free and act forming of a soft mist, which decreases the likelihood of oropharyngeal deposition.

Currently, we have the device known as Respimat ${ }^{\circledR}$ (Boehringer-Ingelheim). This inhaler is available in three forms: ipratropium bromide/salbutamol (Combivent $\left.{ }^{\circledR}\right)$, tiotropium bromide $\left(\right.$ Spiriva $\left.{ }^{\circledR}\right)$, and olodaterol (Striverdi ${ }^{\circledR}$ ).

The drug solution is stored in a foldable bag inside the cartridge of the device. Respimat ${ }^{\circledR}$ has a tension spring that, when bent at $180^{\circ}$, forces a measured volume of drug solution through a capillary tube inside a micropump; once the patient presses the dose release button, the energy released from the spring drives the dose into the uniblock, a unique structural part of this device. The uniblock allows the drug solution to pass through very fine filter channels and releases two jet streams of the drug solution that converge, creating a significant fraction of breathable droplets with low velocity (Fig 3$)^{47}$.

The soft mist inhaler aerosolizes particles with a size between 1 to $5.8 \mu \mathrm{m}$, which helps to avoid the loss of the drug during exhalation and facilitates lung deposition through the sedimentation mechanism ${ }^{48}$, with a pulmonary deposit of around 40 to $53 \%$.

\section{Inhaler selection}

There are important factors when selecting an inhaler (Table 2) ${ }^{49}$. For example, the size of the particle, the patient's preference, the ability to use and generate an appropriate level of inspiratory flow for the device ${ }^{50,51}$, and the advantages and disadvantages described for each of them (Table 3). In the pediatric population there are specific problems that must be taken into account when prescribing an inhaler; for example, it is known that crying reduces the aerosol delivery significantly to the peripheral airways, so it should be recommended a 
Table 2. Comparison of different types of inhalers

\begin{tabular}{|c|c|c|c|c|}
\hline Type and brand & $\begin{array}{c}\text { Size of the } \\
\text { particles }(\mu \mathrm{m})\end{array}$ & Lung deposition (\%) & $\begin{array}{c}\text { Pharyngeal } \\
\text { deposition (\%) }\end{array}$ & $\begin{array}{l}\text { Required inspiratory } \\
\text { flow (liters/min) }\end{array}$ \\
\hline $\begin{array}{l}\text { pMDI } \\
\text { General } \\
\text { PCI + chamber } \\
\text { Fine particles } \\
\text { Innovair }{ }^{\circledR} \\
\text { Alvesco }^{\circledR}\end{array}$ & $\begin{array}{c}1.4-8 \\
2-3.2 \\
1-2 \\
1\end{array}$ & $\begin{array}{c}7.8-34 \\
11.2-68.3 \\
31-34 \\
50-52\end{array}$ & $\begin{array}{c}53.9-82.2 \\
31.2 \\
33-58 \\
32.9\end{array}$ & $\begin{array}{l}20-30 \\
20-30 \\
20-30 \\
20-30\end{array}$ \\
\hline $\begin{array}{l}\text { DPI } \\
\text { General } \\
\text { Single-dose } \\
\text { Aerolizer }^{\circledR} \\
\text { Breezhaler }^{\circledR} \\
\text { Handihaler }^{\circledR}\end{array}$ & $\begin{array}{c}1-2 \\
1.9-7.9 \\
2.8 \\
3.9\end{array}$ & $\begin{array}{c}25-30 \\
13-20 \\
39 \\
17.8\end{array}$ & $\begin{array}{c}70-75 \\
73 \\
45 \\
71\end{array}$ & $\begin{array}{l}30-60 \\
>90 \\
>90 \\
<50\end{array}$ \\
\hline $\begin{array}{l}\text { Multidose } \\
\text { Diskus }^{\circledR} \\
\text { Easyhaler }^{\circledR} \\
\text { Ellipta }^{\circledR} \\
\text { Genuair }^{\circledR} \\
\text { Nexthaler }^{\circledR} \\
\text { Spiromax } \\
\text { Turbuhaler } \\
\text { Twisthaler }^{\circledR}\end{array}$ & $\begin{array}{c}3.5 \\
- \\
2-4 \\
- \\
1.4-1.5 \\
- \\
1.7-5.4 \\
2-2.2\end{array}$ & $\begin{array}{c}7.6 \\
18.5-31 \\
15-27 \\
30.1 \\
56 \\
28-49 \\
14.2-38 \\
36-37\end{array}$ & $\begin{array}{c}- \\
- \\
- \\
54.7 \\
43 \\
- \\
53-71.6 \\
-\end{array}$ & $\begin{array}{c}30-60 \\
<50 \\
<50 \\
60-90 \\
60-90 \\
60-90 \\
50-60 \\
<50\end{array}$ \\
\hline $\begin{array}{l}\text { Soft mist } \\
\text { Respimat }^{\circledR}\end{array}$ & 1- 2 & $40-53$ & 19.3-39 & $20-30$ \\
\hline
\end{tabular}

DPI, dry powder inhaler; PCI, pressurized cartridge inhaler; pMDI, pressurized metered-dose inhaler. Modified from De Ávila et $a^{\mu \rho}$.

Table 3. Advantages and disadvantages of different types of devices

\begin{tabular}{|c|c|c|}
\hline Type of device & Advantages & Disadvantages \\
\hline pMDI & $\begin{array}{l}\text { - Portable and compact } \\
\text { - Difficult to contaminate } \\
\text { - Less expensive than other inhalers } \\
\text { - Dose delivered and particle size is independent of } \\
\text { the inhalation maneuver } \\
\text { - Suitable for emergencies } \\
\text { - Short treatment time } \\
\text { - Available for most drugs formulations }\end{array}$ & $\begin{array}{l}\text { - Slow and deep inhalation }(30 \mathrm{l} / \mathrm{min}) \text { followed by } 10 \mathrm{~s} \\
\text { of holding breath or } \\
\text { - Slow breathing at tidal volume starting immediately } \\
\text { after the device activation } \\
\text { - Activation of only one dose by inhalation }\end{array}$ \\
\hline pMDI with spacer & $\begin{array}{l}\text { - Appropriate for small children and elderly adults } \\
\text { - Reduction of the oropharyngeal deposition } \\
\text { - Suitable for emergencies }\end{array}$ & $\begin{array}{l}\text { - Delay, multiple puffs and static charge reduce lung } \\
\text { bioavailability } \\
\text { - Voluminous: much less portable than pMDI alone } \\
\text { - Most spacers are specifically designed for a pMDI }\end{array}$ \\
\hline DPI & $\begin{array}{l}\text { - Small and portable } \\
\text { - Activated by breath } \\
\text { - Less patient coordination required } \\
\text { - Short treatment time } \\
\text { - Available for most substances }\end{array}$ & $\begin{array}{l}\text { - Moderate to high inspiratory flow is required } \\
\text { - Not suitable for children }<4 \text { years } \\
\text { - It may not be appropriate for emergencies } \\
\text { - Some are sensitive to humidity } \\
\text { - Not suitable for the delivery of large doses of } \\
\text { bronchodilators }\end{array}$ \\
\hline
\end{tabular}

DPI, dry powder inhaler; pMDI, pressurized metered-dose inhaler.

Modified from Broeders et $a^{\text {Fo }}$.

calm environment to increase the comfort of this group of patients during the administration of inhaled medications.
Despite not being included in this review, a nebulizer can be used as a suitable alternative, especially in treating acute symptoms; however, nebulizers are not recommended for 
Table 4. Technique for using a DPI

1. Remove the cap off the inhaler mouthpiece

2. Shake the inhaler (it is not necessary for some HFA pMDIs. The patient should review the instructions booklet)

3. Hold the inhaler upright

4. Breath out completely

5. Place the inhaler mouthpiece between the lips and teeth or place the mouthpiece $4 \mathrm{~cm}$ away from the mouth; keep the tongue down and out of the way of the mouthpiece

6. Trigger the inhaler just after starting a prolonged and profound breath in

7. Continue to breathe in very slowly until the lungs are full (it should take at least 5 seconds to fill your lungs)

8. Remove the inhaler from the mouth and hold your breath while counting to 10 seconds or as long as possible

9. Breath out slowly

HFA, hydrofluoroalkane; pMDI, pressurized metered-dose inhaler. Modified from Sanchis et $a^{5^{3}}$.

Table 5. Technique for using a pMDI with spacer or spacer chamber

1. Remove the cap off the mouthpiece

2. If it is the first time of use, it has not been used for several days, or it has been dropped, activate the inhaler before. Activating the inhaler involves shaking it and triggering it in the air (away from the face) up to four times (check manufacturer's instructions)

3. Insert the pMDI into the spacer

4. Shake the pMDI vigorously for 5 seconds

5. Hold the inhaler upright between your index finger and thumb; you can use the other hand to hold the spacer

6. Breath out normally through your mouth

7. Place the mouthpiece between your teeth and close the lips firmly around the spacer mouthpiece (if you wear a face mask, place it over your nose and mouth)

8. Make sure your tongue does not block the spacer mouthpiece

9. Press the pMDI container with your index finger to release the medication

10. At the same time, inhale deeply and slowly through your mouth until the lungs fill; this will take from 3 to 5 seconds

11. Hold the medicine for 5 to 10 seconds. If you cannot breathe in entirely or cannot hold the breath long enough, you can inhale a second time to empty the spacer and hold the breath again for another 5 seconds

12. If you require more than one shot, wait 15 to 30 seconds between shots. Shake the pMDI again before the next shot. Do not give two shots in the spacer and try to empty it with one inhalation

13. When finished, cover the mouthpiece

14. If your medicine contains a steroid (sometimes called glucocorticoid or corticosteroid), rinse your mouth and make a mouthwash with water after the drug administration. Spit the water, do not swallow it

15. You can use your spacer for more than one medication; remove the first drug to use it with the following medications

pMDI, pressurized metered-dose inhaler.

chronic and continuous therapy because they are more expensive, drug administration is more time consuming and requires more maintenance. Moreover, nebulizers are potential sources of microbial contamination of the respiratory tract: both jet and ultrasonic nebulizers have been associated with nosocomial pneumonia ${ }^{52}$. 
Table 6. Technique for using a DPI Turbuhaler ${ }^{\circledR}$ and Diskus ${ }^{\circledR}$

\section{Turbuhaler technique}

1. Remove the inhaler cap

2. Keep the inhaler upright

3. Rotate the grip counterclockwise and then back until you hear a click

4. Breath out to residual volume

5. Breath out away from the mouthpiece

6. Place the mouthpiece between the teeth and the lips

7. Inhale forcefully and deeply

8. Hold your breath for 5 seconds

9. Exhale away from the mouthpiece (insert the cap after using the Turbuhaler)
Diskus technique

1. Open the inhaler

2. Push the lever back completely

3. Breath out to residual volume

4. Breath out away from the mouthpiece

5. Place the mouthpiece between the teeth and the lips

6. Inhale forcefully and deeply

7. Hold your breath for 5 seconds

8. Exhale away from the mouthpiece

9. Close the inhaler

DPI, dry powder inhaler.

Modified from Basheti et a ${ }^{55}$

\section{Inhalation technique}

Regardless of the recommended device, the patient should be trained on its appropriate use (Tables 4, 5 and 6). Several informative videos are available on the Internet ${ }^{53-55}$.

Despite having adequate therapy when evaluating a patient with uncontrolled asthma symptoms, one question that must be asked is whether the patient is using the prescribed medication. The rates of drug adherence in asthmatic patients are low due to poor control of the disease, exacerbations, high cost of treatment and lack of access to health services.

Patients often misuse their inhalers. In some cases, it has been reported that only 46 to $59 \%$ of patients perform an efficient inhalation technique ${ }^{56}$, and even $25 \%$ of patients have never received training on the proper use of the inhaler ${ }^{57}$. Two systematic reviews about the problems in using inhalers indicate that only $31 \%$ of asthmatics who use spacers do so with an appropriate technique. The most frequent errors are the poor coordination between delivery and inhalation and the inability to hold the breath after the drug is deposited, which occurs in up to $45 \%$ of cases $^{58}$.

Among health professionals, the technique was performed correctly only in $15.5 \%$ of cases, a figure that has decreased in recent years ${ }^{59}$.

To date, there are no series of universal steps to be carried out for all the devices; however, each of them has very similar instructions for use.
Personal or small group demonstrations are the most effective interventions, and it is vital to keep in mind that periodic retraining is always necessary ${ }^{60}$. The inhalation technique improves almost twice (from 57.4\% to $97.9 \%$ ) after three training sessions ${ }^{61}$.

In conclusion, asthma optimal control depends to a large extent on the selected therapy, the device used and the elimination of factors that reduce the adherence to treatment. The selection of the device should always be made jointly with the patient, evaluating the pros and cons of each one of them.

\section{Ethical disclosures}

Protection of human and animal subjects. The authors declare that no experiments were performed on humans or animals for this study.

Confidentiality of data. The authors declare that they have followed the protocols of their work center on the publication of patient data.

Right to privacy and informed consent. The authors declare that no patient data appear in this article.

\section{Conflicts of interest}

The authors declare that they have no conflicts of interest.

\section{Funding}

No funding was received for this review. 


\section{References}

1. Pawankar R, Canonica GW, Holgate ST, Lockey RF, editors. The WAO white book on allergy. United Kingdom: World Allergy Organization; 2011.

2. Worldwide variation in prevalence of symptoms of asthma, allergic rhinoconjunctivitis, and atopic eczema: ISAAC. The International Study of Asthma and Allergies in Childhood (ISAAC) Steering Committee. Lancet. 1998;351:1225-32.

3. Dolovich MB, Dhand R. Aerosol drug delivery: developments in device design and clinical use. Lancet. 2011;377:1032-45.

4. Rottier BL, Rubin BK. Asthma medication delivery: mists and myths. Paediatr Respir Rev. 2013;14:112-8.

5. Bjermer L. The importance of continuity in inhaler device choice for asthma and chronic obstructive pulmonary disease. Respiration. 2014; 88:346-52.

6. Stein SW, Thiel CG. The history of therapeutic aerosols: a chronological review. J Aerosol Med Pulm Drug Deliv. 2017;30:20-41.

7. Sanders M. Inhalation therapy: an historical review. Prim Care Respir J. 2007;16:71-81.

8. Thiel CG. From Susie's question to CFC-free: an inventor's perspective on forty years of MDI development and regulation. Respir Drug Deliv. 1996;1:115-23

9. Nikander K, Nicholls C, Denyer J, Pritchard J. The evolution of spacers and valved holding chambers. J Aerosol Med Pulm Drug Deliv. 2014;27:S4-23.

10. Mitchell JP. What the pulmonary specialist should know about the new inhalation therapies. Eur Respir J. 2012;39:1054-5.

11. Laube BL, Janssens $H M$, de Jongh FH, Devadason SG, Dhand R, Diot $P$, et al. What the pulmonary specialist should know about the new inhalation therapies. Eur Respir J. 2011;39:1308-31.

12. Rottier BL, Rubin BK. Asthma medication delivery: mists and myths. Paediatr Respir Rev. 2013;14:112-8;quiz 118, 137-8.

13. Labiris NR, Dolovich MB. Pulmonary drug delivery. Part I: physiological factors affecting therapeutic effectiveness of aerosolized medications. $\mathrm{Br}$ J Clin Pharmacol. 2003;56:588-99.

14. Muchão FP, Filho LV. Advances in inhalation therapy in pediatrics. J Pediatr (Rio J). 2010;86:367-76.

15. Haughney J, Price D, Barnes NC, Virchow JC, Roche N, Chrystyn H. Choosing inhaler devices for people with asthma: current knowledge and outstanding research needs. Respir Med. 2010;104:1237-45.

16. Self TH, Pinner NA, Sowell RS, Headley AS. Does it really matter what volume to exhale before using asthma inhalation devices? J Asthma. 2009;46:212-6.

17. Cheng YS. Mechanisms of pharmaceutical aerosol deposition in the respiratory tract. AAPS PharmSciTech. 2014;15:630-40.

18. Myers TR. The science guiding selection of an aerosol delivery device. Respir Care. 2013;58:1963-73.

19. Dal-Negro RW. Dry powder inhalers and the right things to remember: a concept review. Multidiscip Respir Med. 2015;10:13.

20. Dolovich MB, Ahrens RC, Hess DR, Anderson P, Dhand R, Rau JL; American College of Chest Physicians, American College of Asthma, Allergy and Immunology. Device selection and outcomes of aerosol therapy: evidence-guidelines. Chest. 2005;127:335-71.

21. Amirav I, Newhouse MT, Mansour Y. Measurement of peak inspiratory flow with in-check dial device to simulate low-resistance (Diskus) and high resistance (Turbohaler) dry powder inhalers in children with asthma. Pediatr Pulmonol. 2005;39:447-51.

22. Smaldone GC. Drug delivery via aerosol systems: concept of "aerosol inhaled". J Aerosol Med. 1991;4:229-35.

23. Hendeles L, Colice GL, Meyer RJ. Withdrawal of albuterol inhalers containing chlorofluorocarbon propellants. N Engl J Med. 2007:356:1344-51.

24. Vaswani SK, Creticos PS. Metered dose inhaler: past, present, and future. Ann Allergy Asthma Immunol. 1998;80:11-9.

25. Cummings RH. Pressurized metered dose inhalers: chlorofluorocarbon to hydrofluoroalkane transit ion-valve performance. J Allergy Clin Immunol. 1999;104:S230-6.

26. Newman SP. Principles of metered-dose inhaler design. Respir Care. 2005;50:1177-90.

27. Azouz W, Chrystyn H. Clarifyng the dilemas about inhalation techniques for dry powder inhalers: integrating science with clinical practice. Prim Care Respir J. 2012;21:208-13.

28. Ibrahim M, Verma R, Garcia-Contreras L. Inhalation drug delivery devices: techonology update. Med Devices (Auckl). 2015;8:131-9

29. Adkinson Jr. NF, Bochner BS, Burks AS, Busse WW, Holgate ST, Lemanske Jr. RF, et al. Middleton's allergy: principles and practice. Maryland: Elsevier; 2008. pp. 1-1924.

30. Newman SP, Newhouse MT. Effect of add-on devices for aerosol drug delivery: deposition studies and clinical aspects. J Aerosol Med. 1996;9:55-70.

31. Nair A, Menzies D, Hopkins P, McFarlane L, Lipworth BJ. In vivo comparison of the relative systemic bioavailability of fluticasone propionate from three antistatic spacers and a metered dose inhaler. $\mathrm{Br} \mathrm{J}$ Clin Pharmacol. 2009;67:191-8.
32. Nair A, Menzies D, Barnes M, Burns P, McFarlane L, Lipworth BJ. Respirable dose delivery of fluticasone propionate from a small valved holding chamber, a compact breath actuated integrated vortex device and a metered dose inhaler. Br J Clin Pharmacol. 2008;66:20-6.

33. Liu CL, Lu YT. Bronchodilatation effects of a small volume spacer used with a metered-dose inhaler. J Asthma. 2009;46:637-41.

34. Berger WE, Bensch GW, Weinstein SF, Skoner DP, Prenner BM, Shekar T, et al. Bronchodilation with mometasone furoate/formoterol fumarate administered by metered-dose inhaler with and without a spacer in children with persistent asthma. Pediatr Pulmonol. 2014;49:441-50.

35. Dolovich M. Lung dose, distribution, and clinical response to therapeutic aerosols. Aerosol Sci Tech. 1993;18:230-40.

36. Slator L, von Hollen D, Sandell D, Hatley RH. In vitro comparison of the effect of inhalation delay and flow rate on the emitted dose from three valved holding chambers. J Aerosol Med Pulm Drug Deliv. 2014; 27:S37-43.

37. Wildhaber JH, Waterer GW, Hall GL, Summers QA. Reducing electrostatic charge on spacer devices and bronchodilator response. $\mathrm{Br} \mathrm{J}$ Clin Pharmacol. 2000;50:277-80.

38. Rau JL, Coppolo DP, Nagel MW, Avvakoumova VI, Doyle CC, Wiersema KJ, et al. The importance of nonelectrostatic materials in holding chambers for delivery of hydrofluoroalkane albuterol. Respir Care. 2006;51:503-10.

39. Anhoj J, Bisgaard $\mathrm{H}$, Lipworth BJ. Effect of electrostatic charge in plastic spacers on the lung delivery of HFA-salbutamol in children. $\mathrm{Br} \mathrm{J} \mathrm{Clin}$ Pharmacol. 1999;47:333-6.

40. Janssens HM, Heijnen EM, de Jong VM, Hop WC, Holland WP, de Jongste JC, et al. Aerosol delivery from spacers in wheezy infants: a daily life study. Eur Respir J. 2000;16:850-6.

41. Piérart F, Wildhaber JH, Vrancken I, Devadason SG, Le Souëf PN. Washing plastic spacers in household detergent reduces electrostatic charge and greatly improves delivery. Eur Respir J. 1999;13:673-8.

42. Bell JH, Hartley PS, Cox JSG. Dry powder aerosol I: a new powder inhalation device. J Pharm Sci. 1971;60:1559-64.

43. Atkins PJ. Dry powder inhalers: an overview. Respir Care. 2005;50:1304-12.

44. Muralidharan P, Hayes D Jr, Mansour HM. Dry powder inhalers in COPD, lung inflammation and pulmonary infections. Expert Opin Drug Deliv. 2015;12:947-62

45. Weers J, Clark A. The impact of inspiratory flow rate on drug delivery to the lungs with dry powder inhalers. Pharm Res. 2017:34:507-28.

46. Mehta P. Dry powder inhalers: a focus on advancements in novel drug delivery systems. J Drug Deliv. 2016;2016:8290963.

47. Dalby RN, Eicher J, Zierenberg B. Development of Respimat ${ }^{\circledR}$ Soft Mis$\mathrm{t}^{\mathrm{TM}}$ inhaler and its clinical utility in respiratory disorders. Med Devices (Auckl). 2011;4:145-55

48. Dahl R, Kaplan A. A systematic review of comparative studies of tiotropium Respimat ${ }^{\circledR}$ and tiotropium HandiHaler ${ }^{\circledR}$ in patients with chronic obstructive pulmonary disease: does inhaler choice matter? CBMC Pulm Med. 2016;16:135

49. De Ávila Cabezón GR, González Rey J, Balaguer Balaguer EM. Las 4 reglas de la terapia inhalada. Galicia: Sogami; 2015

50. Broeders ME, Sanchis J, Levy ML, Crompton GK, Dekhuijzen PN; ADMIT Working Group. The ADMIT series-issues in inhalation therapy. 2. Improving technique and clinical effectiveness. Prim Care Respir J. 2009;18:76-82.

51. Pedersen S, Dubus JC, Crompton GK; ADMIT Working Group. The ADMIT series-issues in inhalation therapy. 5. Inhaler selection in children with asthma. Prim Care Respir J. 2010;19:209-16.

52. Ida $Y$, Ohnishi H, Araki K, Saito R, Kawai S, Watanabe T. Efficient management and maintenance of ultrasonic nebulizers to prevent microbial contamination. World J Methodol. 2016:6:126-32.

53. Sanchis J, Corrigan C, Levy ML, Viejo JL; ADMIT Group. Inhaler devices-from theory to practice. Respir Med. 2013;107:495-502.

54. Youtube.com [Internet]. Available from: https://youtu.be/nSmf1rm1pnw; https://youtu.be/2n4eylibyFY; https://youtu.be/jKVrOyu_p94; https://youtu. be/ZaRxwcpyduk; https://youtu.be/bJAF_g4sC6l.

55. Basheti IA, Bosnic-Anticevich SZ, Armour CL, Reddel HK. Checklists for powder inhaler technique: a review and recommendations. Respir Care. 2014;59:1140-54

56. Cochrane MG, Bala MV, Downs KE, Mauskopf J, Ben-Joseph RH. Inhaled corticosteroids for asthma therapy: patient compliance, devices, and inhalation technique. Chest. 2000;117:542-50

57. Molimard M, Raherison C, Lignot S, Depont F, Abouelfath A, Moore N. Assessment of handling of inhaler devices in real life: an observational study in 3811 patients in primary care. J Aerosol Med. 2003;16:249-54.

58. Sanchis J, Gich I, Pedersen S; Aerosol Drug Management Improvement Team (ADMIT). Systematic review of errors in inhaler use: has patient technique improved over time? Chest. 2016;150:394-406.

59. Plaza V, Giner J, Rodrigo GJ, Dolovich MB, Sanchis J. Errors in the use of inhalers by health care professionals: a systematic review. J Allergy Clin Immunol Pract. 2018:6:987-95

60. Scichilone N. Asthma control: the right inhaler for the right patient. Adv Ther. 2015;32:285-92.

61. Sumino K, Cabana MD. Medication adherence in asthma patients. Curr Opin Pulm Med. 2013;19:49-53. 